\title{
Molecular Docking and In Silico Study of Denileu- kin Diftitox: Comparison of Wild Type With C519S- Mutant
}

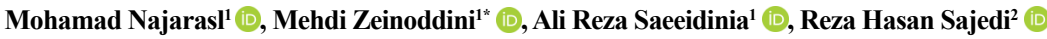

1. Department of Bioscience and Biotechnology, Faculty of Chemistry and Chemical Engineering, Malek Ashtar University of Technology, Tehran, Iran 2. Department of Biochemistry, Faculty of Biological Sciences, Tarbiat Modares University, Tehran, Iran.

\begin{tabular}{|c|c|}
\hline $\begin{array}{l}\text { Use vour device toscan } \\
\text { and read the article online }\end{array}$ & \\
\hline 口itrig & $\begin{array}{l}\text { Cittation Najarasl M, Zeinoddini M, Saeeidinia AR, Hasan Sajedi R. Molecular Docking and In Silico Study of Denileu- } \\
\text { kin Diftitox: Comparison of Wild Type With C519S-Mutant. Research in Molecular Medicine. 2020; 8(2):83-92. https://doi. } \\
\text { org/10.32598/rmm.8.2.903.6 }\end{array}$ \\
\hline 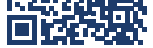 & doif https://doi.org/10.32598/rmm.8.2.903.6 \\
\hline
\end{tabular}

\section{(1) (8)}

Article Type:

Research Article

\section{Article info:}

Received: 2 Jan 2020

Revised: 10 Feb 2020

Accepted: 10 Mar 2020

Keywords:

Immunotoxin, Denileukin diftitox, Refolding process, Prediction, Bioinformatics software, Docking

\begin{abstract}
A B S T RA C T
Background: Denileukin diftitox (trade name, Ontak) is the first recombinant Immunotoxin (IM), in which the binding domain of diphtheria toxin has been replaced by the amino acid sequence of human interleukin-2 (DT389IL-2) using genetic engineering. Purity, stability, and structural property of the protein are critical factors for the scale-up production of this fusion protein. In this IM, location 519 has free cysteine residue that leads to cross S-S bound formation in the refolding process and, as a result, misfolding/aggregation of the protein may occur.

Materials and Methods: To inhibit misfolding/aggregation, we substituted cysteine 519 by a serine residue with site-directed mutagenesis, and then the ability of the mutated protein for binding to the IL-2 receptor was predicted and determined by bioinformatics tools. For this purpose, the sequence of the denileukin diftitox was adopted from Drugbank, and the mentioned substitution applied. Two methods determined the folding of the fusion protein: de novo modeling method (by utilizing the I-TASSER database) and homology modeling method (by using some databases and tools, including Swiss-Model, PHYRE2, M4T, ModWeb, RaptorX, and EasyModeller). Finally, the ability of the proteins for binding to the IL-2 receptor was investigated by pyDock and Zdock docking servers, as well as Hex software.

Results: The result showed that the mutated form (C519S) of this protein folds appropriately, and the $\Delta \mathrm{G}$ of the models, measured by STRUM, showed no significant variation. Also, docking analysis has shown that the protein can efficiently bind to the IL-2 receptor without any substantial changes in the binding energy.

Conclusion: The present study shows that the suggested mutation of this protein can be an acceptable replacement for denileukin diftitox with a similar affinity and a more proper refolding process.
\end{abstract}

\footnotetext{
* Corresponding Author:

Mehdi Zeinoddini, PhD.

Address: Department of Bioscience and Biotechnology, Faculty of Chemistry and Chemical Engineering, Malek Ashtar University of Technology, Tehran, Iran Phone: +98 (21) 22974604

E-mail: zeinoddini52@mut.ac.ir
} 


\section{Introduction}

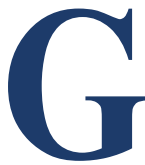

enetic engineering has revolutionized many biology-related industries, including pharmacology and medicine [1]. For a long time, the data derived from the computational procedure (or "in silico" approach) were not much trusted by most experimental investigators due to the notorious local minimum problem. They only believed in the experimental data and thought that computational outputs are not reliable. But the circumstance has changed during the last decade with the rapid development of structural and sequential bioinformatics. Also, the knowledge of three-dimensional protein structure or their ligand-binding complexes is vital for rational drug design and development. Although crystallography with X-ray is a powerful device in determining protein structures, it is costly and time-consuming.

Besides, crystallization of all proteins cannot be successful; for example, crystallizing of membrane proteins is very difficult because most of them cannot be dissolved in ordinary solvents. As a result, a few membrane proteins have been discovered so far. Nuclear Magnetic Resonance (NMR) spectroscopy is a potent technique [2] to determine the Three Dimensional (3D) structure of membrane proteins, but it is also costly, time-consuming, and laboratories. In these fields, a series of 3D protein structures methods developed to receive of the structural information effectively and with employing structural bioinformatics tools [3].

Currently, due to the rapid growth of biological sequences discovered in the post-genomic area and their timely use for drug design and production, a lot of critical sequence-based information using the computational biology has played increasingly important roles in stimulating and the evaluation of new pharmaceutical proteins production. Several protein therapeutic drugs have been produced by this strategy [4-6]. Denileukin diftitox or Ontak (sequence accession number: DB00004, PDB code of structures which using in prediction: $1 \mathrm{~m} 47-1 \mathrm{f} 01$ -1pw6-1dtp- 1mdt) is an engineered fusion protein composed of two parts: a fragment or truncated part of diphtheria toxin (Met1-Thr387), as the catalytic and effector part, and a piece of IL-2 cytokine (Ala1- Thr133), as targeting moiety [7]. After concluding, this fusion protein is named DT389IL-2. The protein binds to cells expressing the high-affinity IL-2 receptor (IL-2R, PDB: 2ERJ ) and internalized by endocytosis [8].

In the cell, this immunotoxin inhibits protein synthesis and leads to cell death. Ontak was the first immuno- toxin, which received the FDA's approval in 2000 [9]. It has been used in the treatment of recurrent Cutaneous T-Cell Lymphoma (CTCL), Hodgkin Disease (HD), adult T-cell leukemia (ATL), and other types of leukemia and lymphomas in which overexpression of IL-2R occurs [10]. However, because of the lack of stability of the drug, its production was subject to customer demand.

Denileukin diftitox is composed of 521 amino acid residues with a molecular weight of $58 \mathrm{kD}$. The isoelectric $\mathrm{pH}$ (pI) of this protein is about 5.5, so it is an acidic protein [11] One of the major problems in denileukin diftitox production is improper folding of the protein. There are three cysteine residues in IL-2 moiety of the protein [12], and one of those does not take part in disulfide binding (Cys519), so it is possible to substitute this amino acid, which is not essential for the activity of the protein [13] Free thiol groups which interest in thiol-disulfide interactions can facilitate aggregation by creating new intraand inter-molecular bonds [14, 15].

At the same time, it is free to form an undesirable intermolecular linkage with another residue that may help address this problem [16]. However, the substitution may affect the folding and the physiological behavior of the protein. Bioinformatics tools are exploited to evaluate this possibility. Bioinformatics tools are increasingly being used for the in silico analysis of different biological issues [17]. These tools can be used for analyzing the structural changes following the alteration in the sequence of a protein, the affinity of a protein to bind to different molecules, the stability of a protein, the possibility of the expression of a protein in a defined expression system, and so on [18].

In the present study, cysteine 519 of DT389IL-2 protein is substituted by a serine residue, and changes in the structure and function of the mutant protein are investigated through bioinformatics analysis.

\section{Materials and Methods}

\section{Adoption of DT389IL-2 sequence}

The sequence of DT389IL-2 protein was adopted from the Drugbank (https://www.drugbank.ca/) with the accession number of DB00004 and saved as FASTA format.

\section{Structural modeling of DT389IL-2}

Protein modeling is carried out through two common strategies: de novo modeling, which is an algorithmic process by which the tertiary structure of a protein is deter- 
mined based on its primary sequence; and homology modeling, which employs the previously resolved structures of the structurally related proteins [19]. De novo modeling is performed using the I-TASSER database (https://zhanglab. ccmb.med.umich.edu/I-TASSER/). Homology modeling is carried out by the Swiss-Model server at (https://swissmodel.expasy.org/), PHYRE2 protein fold recognition server (http://www.sbg.bio.ic.ac.uk/phyre2/html/ page.cgi), M4T database (http://manaslu.fiserlab.org/M4T), ModWeb, a comparative protein structure modeller (https://modbase. compbio.ucsf.edu/modweb/) RaptorX web server (http:// raptorx.uchicago.edu/StructurePrediction/predict/), and EasyModeller (https://blast.ncbi.nlm.nih.gov/Blast.cgi).

\section{Model assessment}

The quality of the predicted structures is validated using MolProbity (http://molprobity.biochem.duke.edu/). SAVES server is also used for further validation of the structure (http://servicesn.mbi.ucla.edu/SAVES).

\section{Molecular docking study}

To validate the efficiency and to compare the binding of the DT389IL-2, C519S-mutated, and IL-2 cytokine to the IL-2 receptor, we performed molecular docking using HEX 6.0 software. The applied parameters for this study were as follows: FFT mode - 3d fast life, distant range -40 , twist range -360 , ligand range -180 , receptor range -180 , and grind dimension -0.6 . Finally, the obtained complex from the docking study was analyzed using the protein interaction calculator of the pyDock server (https://ife.bsc.es/servlet/pydock/ home/), which performs rigid docking using interaction restraints. Be- sides, ZDock server, an interactive docking predictor (http://zdock.umassmed.edu) was also used.

\section{Results}

The amino acid sequence of DT389IL-2

Figure 1 displays the primary structure of DT389IL-2 protein. As can be seen, it is composed of 521 amino acid residues.

\section{Tertiary structure prediction}

Figure 2 shows the three-dimensional structures of DT389IL-2 and C519S-mutated by I-TASSER. The best-predicted models were selected based on local quality plots and Z-scores.

\section{Model assessment}

Table 1 presents the assessment of the predicted 3D structures using the MolProbity server. Poor and favored rotamers, Ramachandran outliers and favored, bad bonds, bad angles, cis pralines, cis non-prolines, and twisted peptides are determined for the predicted structures by all the mentioned methods. Also, Table 2 presents the validation of the proposed structures done by SAVES.

As it can be deducting from the obtained data, EasyModeller proposed structures were selected for further analysis of the affinity of the proteins to the IL-2 receptor.

\section{Molecular docking study}

To investigate and compare the binding affinity of DT389IL-2, C519S-mutated, and IL-2 proteins to the

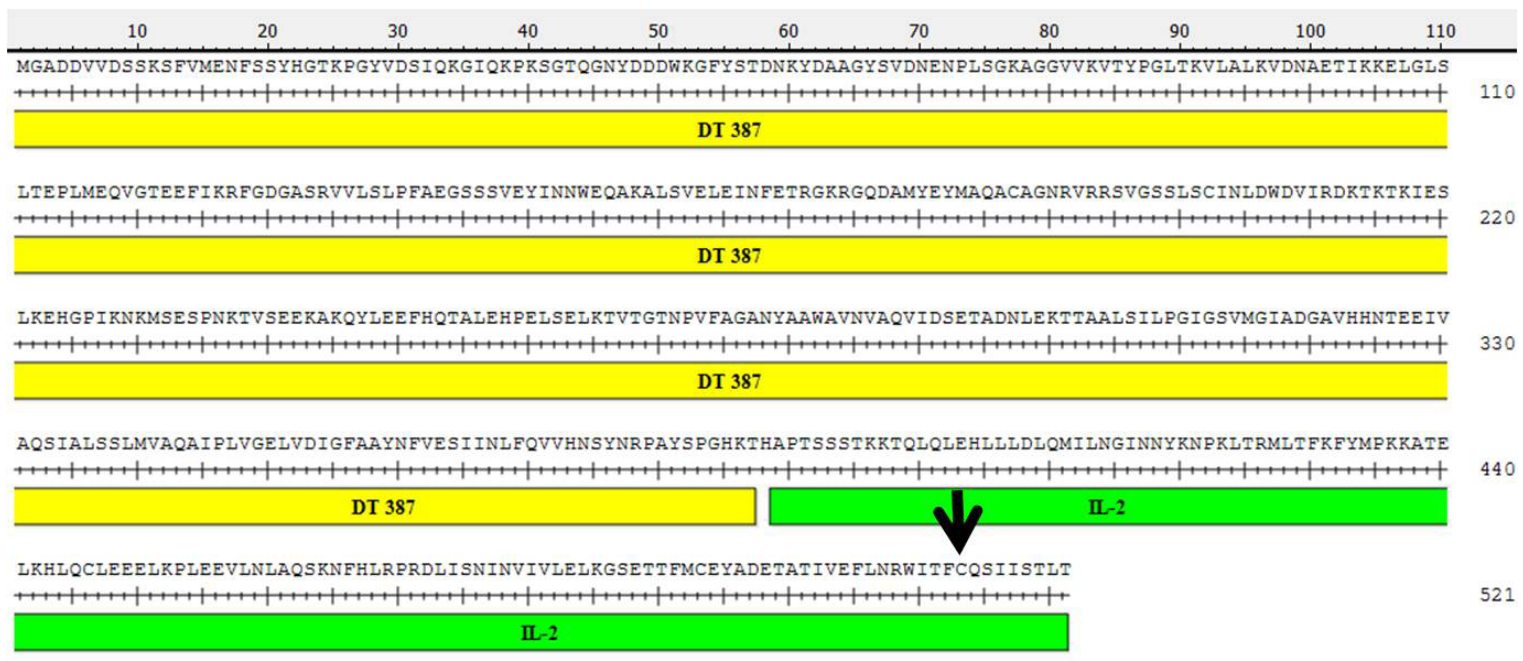

Figure 1. Amino acid sequence of DT389IL-2 protein, adopted from Drugbank database 

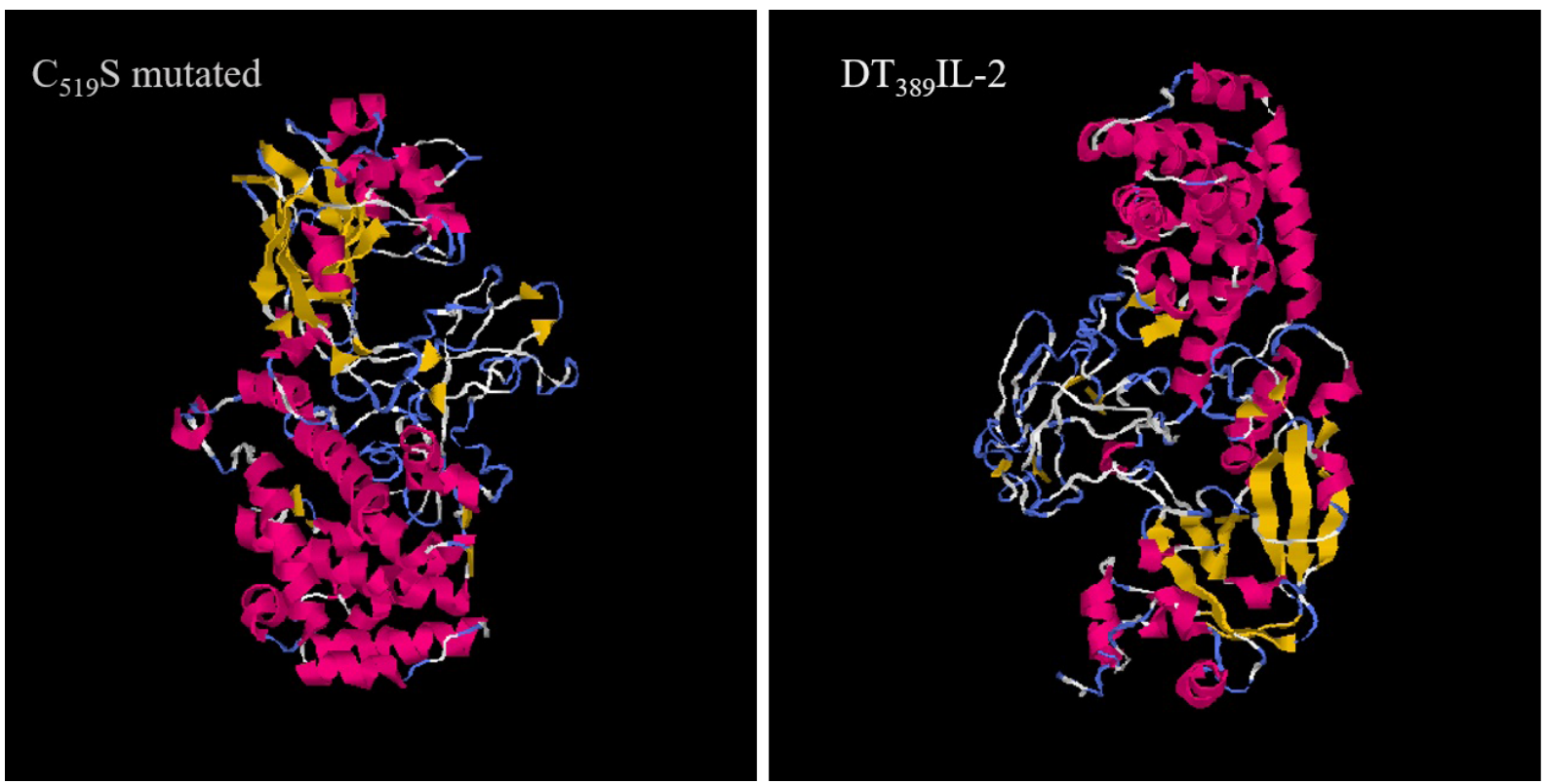

Figure 2. The 3D structure of DT389IL-2 and C519S-mutated predicted by I-TASSER software

\section{Denileukin diftitox}

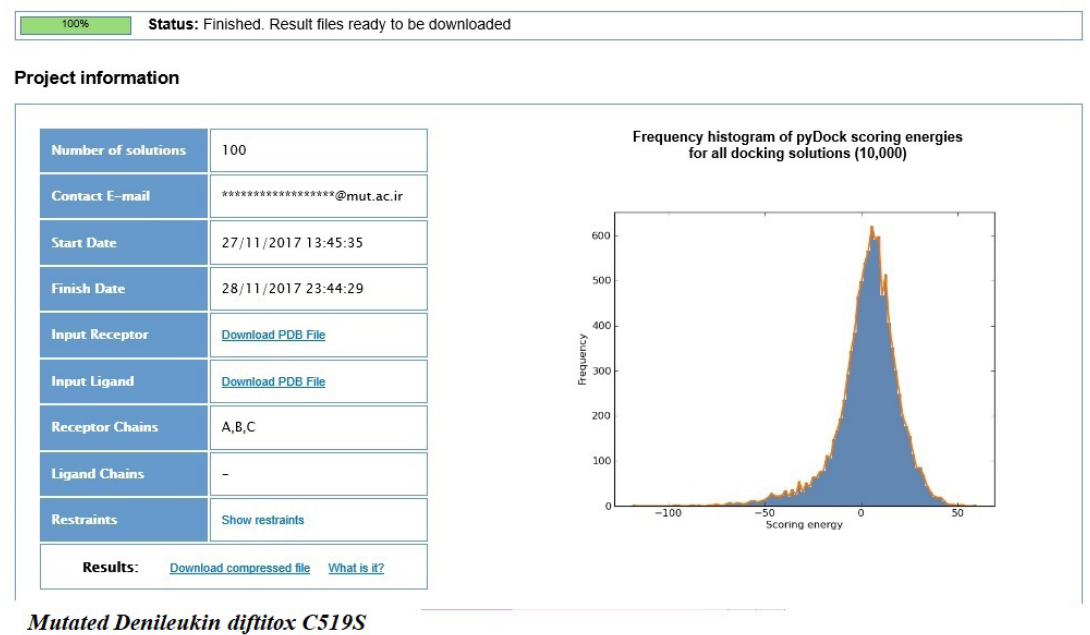

Mutated Denileukin diftitox C519S

\begin{tabular}{|l|l|}
\hline Status: Finished. Result files ready to be downloaded \\
\hline
\end{tabular}

Project information

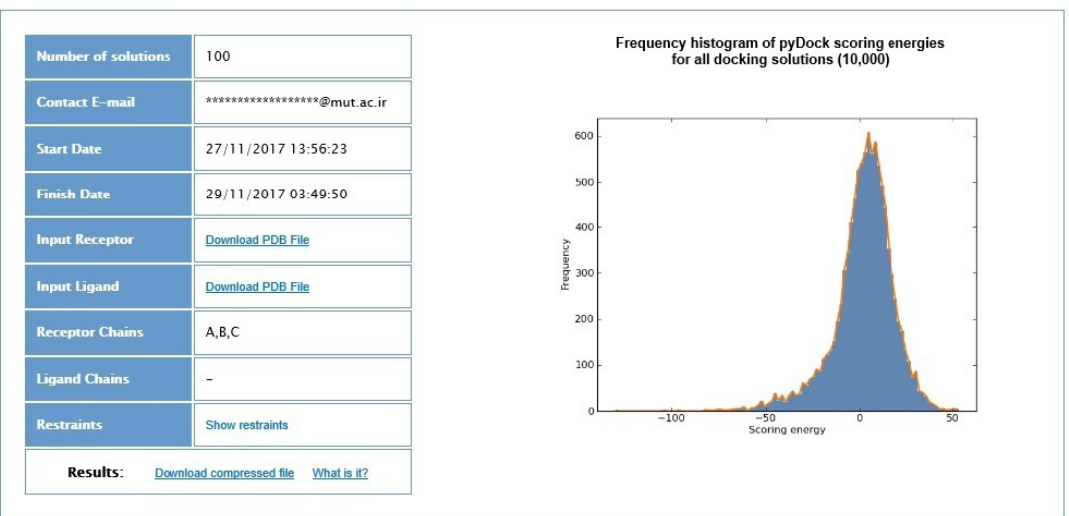

Figure 3. Binding affinity of DT389IL-2 and C519S-mutated to IL-2 receptor using Pydock web server 

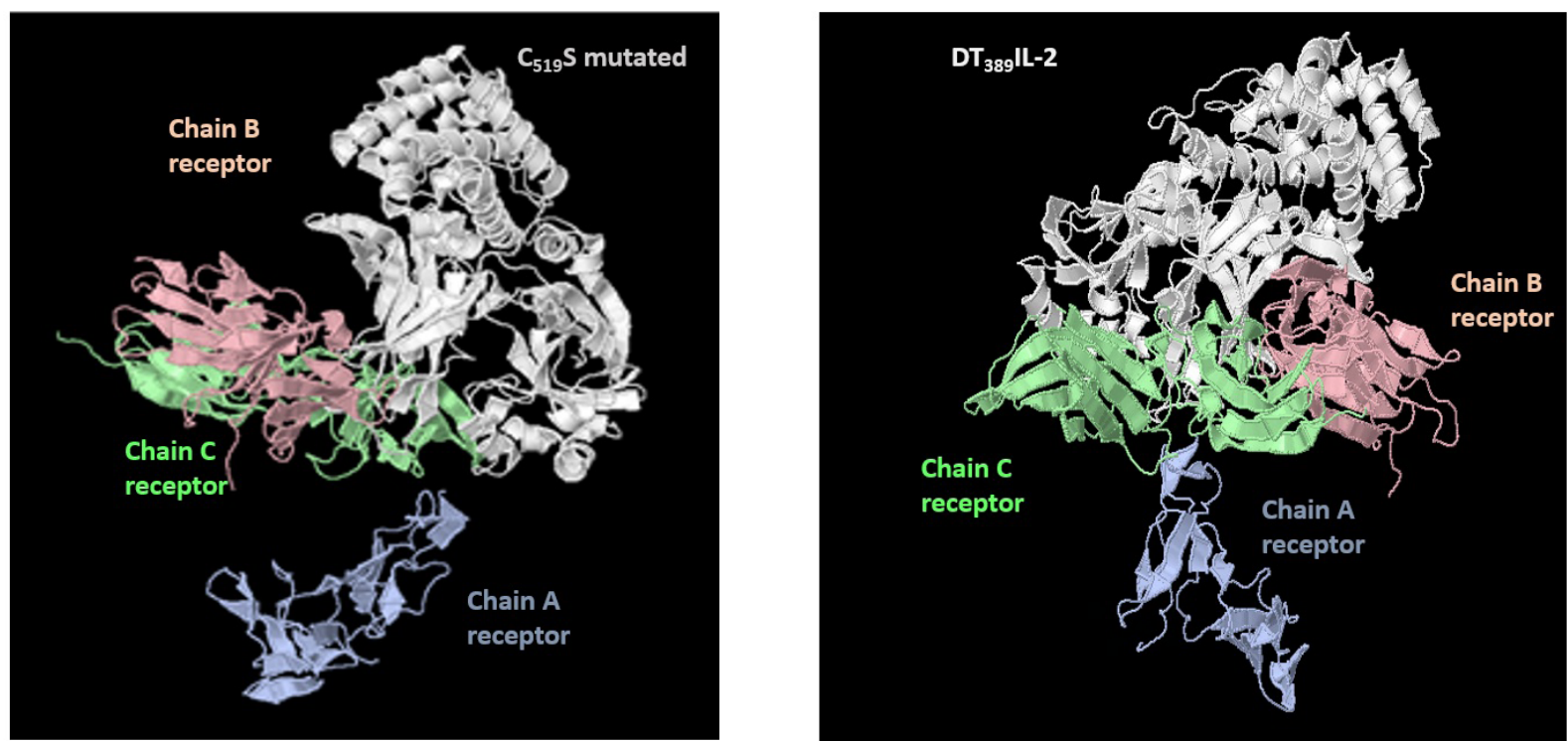

Figure 4. Binding affinity of DT389IL-2 and C519S-mutated to IL-2 receptor by Pydock web server

grmm

IL-2 receptor, we performed a docking study by the mentioned servers. Asp20 and His133 residues from IL-2 and IL-2 receptor, respectively, were selected as the interacting residues. Glu403 and His138, respectively, from C519S-mutated, and DT389IL-2 were also considered as the interacting residues. Table 3 presents the binding energy of each protein.

The results show no significant difference between DT389IL-2 and C519S-mutated regarding the binding ability to the receptor.

Also, the result of the pyDock web server, which was presented in figures 3 and 4, indicates that C519S-mutated can efficiently bind to the IL-2 receptor, and there is no significant difference between these two proteins in this regard.

Analyses by the ZDock server further confirmed the binding efficiency of DT389IL-2 and C519S-mutated to their receptor (Figure 5).

Analysis of binding efficiency of the three proteins using Hex software resulted in the following data: $\Delta \mathrm{G}$ of binding of IL-2, DT389IL-2, and C519S-mutated to IL-2 receptor were $-893.3,-527.9$ and -565.4 , respectively, which confirms that C519S-mutated can bind to IL-2 receptor more efficiently than DT389IL-2.
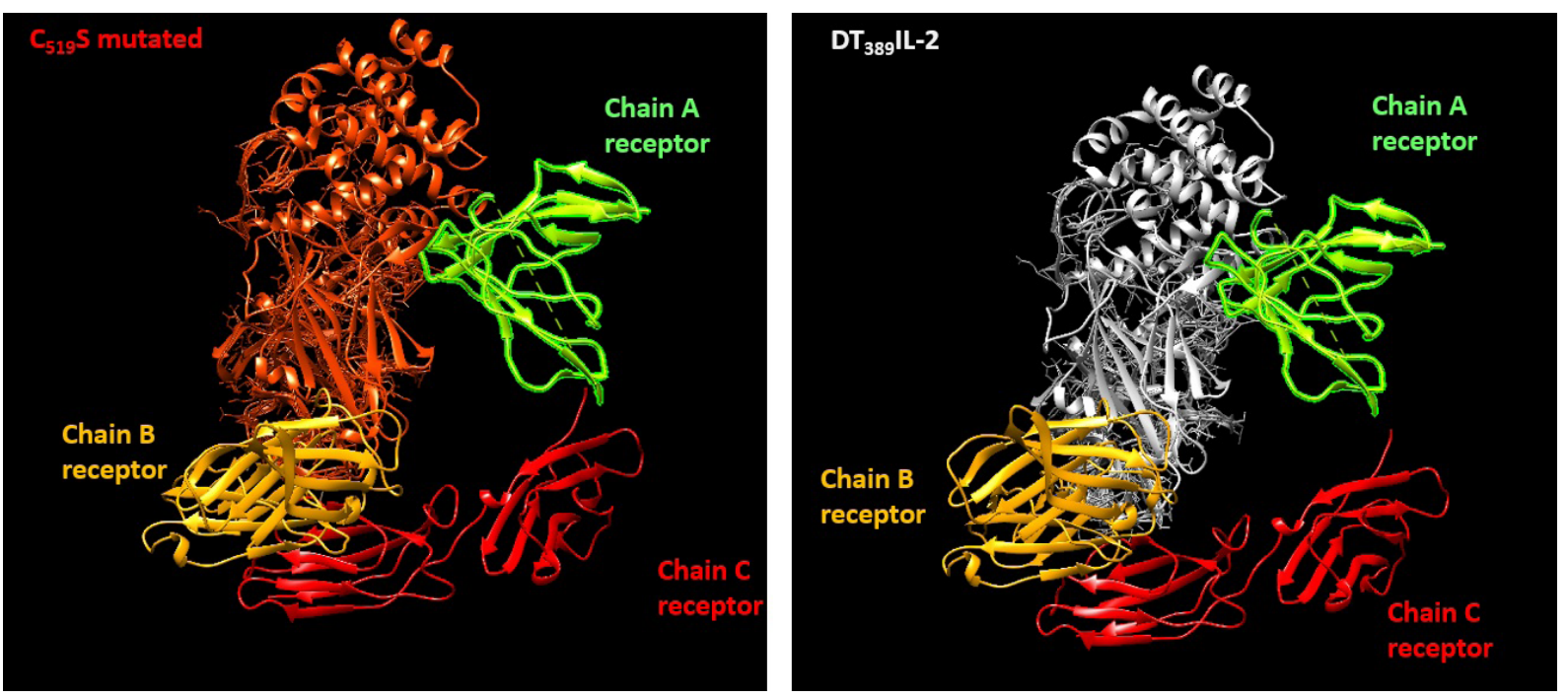

Figure 5. Binding affinity of DT389IL-2 and C519S-mutated to IL-2 receptor by ZDock web server 
Table 1. Assessment of the 3D structures using MolProbity server

\begin{tabular}{|c|c|c|c|c|c|c|c|c|}
\hline Factors & I-TASSER & Swiss-Model & Phyre2 & M4T & ModWeb & RaptorX & Easy Modeller & 1Mdt \\
\hline Poor rotamers & 15.14 & 6.25 & 8.69 & 3.82 & 2.49 & 4.45 & 5.35 & 10.26 \\
\hline Favored rotamers & 70.16 & 86.96 & 84.19 & 89.74 & 94.75 & 88.42 & 87.97 & 80.88 \\
\hline Ramachandran outliers & 12.52 & 1.56 & 4.24 & 2.12 & 0.52 & 1.35 & 3.85 & 1.25 \\
\hline Ramachandran favored & 73.80 & 95.84 & 86.32 & 93.44 & 97.66 & 94.41 & 91.71 & 95.18 \\
\hline$C \beta$ deviations $>0.25 \AA$ & 13.52 & 0.84 & 6.97 & 3.29 & 0.56 & 1.23 & 6.35 & 1.45 \\
\hline Bad bonds & 0.15 & 0 & 0.58 & 0.70 & 0 & 0.12 & 1.36 & 0.90 \\
\hline Bad angles & 3.70 & 0.37 & 3.72 & 1.36 & 1.20 & 1.48 & 3.49 & 0.39 \\
\hline Cis Prolines & 5.26 & 0 & 0 & 0 & 0 & 0 & 0 & 0 \\
\hline Cis nonProlines & 0.60 & - & - & - & - & - & - & - \\
\hline Twisted peptides & 13.65 & - & 0.58 & 0.39 & - & - & 0.38 & - \\
\hline
\end{tabular}

Table 2. Validation of the structures using SAVES server

\begin{tabular}{|c|c|c|c|c|c|c|c|c|}
\hline Program & I-TASSER & Swiss-Model & PHYRE2 & M4T & ModWeb & RaptorX & EasyModeller & 1Mdt \\
\hline Verify3D & 86.37 & 95.35 & 95.39 & 75.72 & 94.04 & 69.48 & 76.20 & 97.51 \\
\hline ERRAT & 77.193 & 95.1743 & 64.9123 & 78.726 & 84.4262 & 71.2049 & 64.3275 & 90 \\
\hline PROCHECK & $\begin{array}{c}\text { Errors: } 7 \\
\text { Warning: } 1 \\
\text { Pass: } 1\end{array}$ & $\begin{array}{l}\text { Errors: } 0 \\
\text { Warning: } 6 \\
\text { Pass: } 2\end{array}$ & $\begin{array}{l}\text { Errors: } 5 \\
\text { Warning: } 3 \\
\text { Pass: } 1\end{array}$ & $\begin{array}{l}\text { Errors: } 4 \\
\text { Warning: } 2 \\
\text { Pass: } 2\end{array}$ & $\begin{array}{c}\text { Errors: } 3 \\
\text { Warning: } 2 \\
\text { Pass: } 3\end{array}$ & $\begin{array}{l}\text { Errors: } 3 \\
\text { Warning: } 2 \\
\text { Pass: } 3\end{array}$ & $\begin{array}{l}\text { Errors: } 4 \\
\text { Warning: } 2 \\
\text { Pass: } 2\end{array}$ & $\begin{array}{c}\text { Errors: } 3 \\
\text { Warning: } 4 \\
\text { Pass: } 1\end{array}$ \\
\hline
\end{tabular}

\section{Discussion}

DAB389IL-2 is a recombinant immunotoxin composed of a catalytic moiety of diphtheria toxin fused to the binding moiety of IL-2 [20]. In the purification prosses of Ontak, many problems are showing up, including misfolding and instability [21]. In the present study, to solve these problems, the molecular and structural studies were exploited. Through mutagenesis in the IL-2 subunit, it may be possible to overcome the problem of Ontak misfolding and instability. IL-2 has three cysteine residues, Cys58, Cys105, and Cys125. Cys58 and Cys 105 are involved in disulfide bond formation, but not Cys125. This issue can result in protein misfolding [22].

Since cysteine residues are not essential for the activity of the protein, they are free to form undesirable intermolecular or intramolecular linkages, which can cause the problem. In aldesleukin (recombinant IL-2), this issue was solved by the replacement of an amino acid residue of the protein (Cysteine 125 substituted with a serine residue). Since Ontak also has the same structure in the IL-2 part, the possibility of the proper folding may increase if another residue substitutes one of the cysteine residues in this moiety of the fusion protein. In the present study, we replaced Cys519 (Cys125 of the IL-2 moiety) with a serine residue and analyzed the proper folding, as well as the ability of the mutated protein to bind to IL-2 receptor using bioinformatics tools.

In this silico study, we showed that substitution of Cys 519 by a serine residue in DT389IL-2 protein has neither any significant effect on the tertiary structure of this protein nor on the binding efficiency of this protein to IL-2 R. This substitution was performed to prevent false crosslinkage between Cys519 and two other cysteine residues in IL-2 moiety of DT389IL-2, and as a result preventing from misfolding of the protein. Also, tertiary structure prediction was carried out by both de novo and homology modeling strategies. Prediction of the 3D structure of DT389IL-2 and C519S-mutated via the I-TASSER database, which uses de novo strategy, showed no significant change in the structure of these two proteins. The other used software and tools also confirmed this result. Model 
Table 3. The binding affinity of DT389IL-2 (left tab), C519S-mutated (middle tab) and IL-2 proteins (right tab) to the IL-2 receptor

\begin{tabular}{|c|c|c|c|}
\hline \multirow[b]{2}{*}{ Cluster } & \multicolumn{3}{|c|}{$\begin{array}{c}\text { Job Details: } \mathrm{DT}_{389} \text { IL-2 } \\
E={ }_{0.40} \mathrm{E}_{\text {rep }+-0.40} \mathrm{E}_{\text {att }+600} \mathrm{E}_{\text {elec }+1.00} \mathrm{E}_{\text {DARS }}\end{array}$} \\
\hline & Members & Representative & Weighted Score \\
\hline \multirow{3}{*}{0} & & Center & -1019.2 \\
\hline & 88 & & \\
\hline & & Lowest Energy & -1150.2 \\
\hline \multirow{3}{*}{1} & & Center & -1007.1 \\
\hline & 56 & & \\
\hline & & Lowest Energy & -1163.2 \\
\hline \multirow{3}{*}{2} & & Center & -1002.9 \\
\hline & 47 & & \\
\hline & & Lowest Energy & -1070.0 \\
\hline \multirow{3}{*}{3} & & Center & -952.9 \\
\hline & 46 & & \\
\hline & & Lowest Energy & -1055.5 \\
\hline \multirow{3}{*}{4} & & Center & -905.5 \\
\hline & 45 & & \\
\hline & & Lowest Energy & -1124.6 \\
\hline \multirow{3}{*}{5} & & Center & -1077.4 \\
\hline & 40 & & \\
\hline & & Lowest Energy & -1167.2 \\
\hline \multirow{3}{*}{6} & & Center & -1034.0 \\
\hline & 29 & & \\
\hline & & Lowest Energy & -1149.0 \\
\hline \multirow{3}{*}{7} & & Center & -902.2 \\
\hline & 29 & & \\
\hline & & Lowest Energy & -1052.9 \\
\hline \multirow{3}{*}{8} & & Center & -874.2 \\
\hline & 27 & & \\
\hline & & Lowest Energy & -1089.7 \\
\hline
\end{tabular}

\begin{tabular}{|c|c|c|c|}
\hline \multirow[b]{2}{*}{ Cluster } & \multicolumn{2}{|c|}{$\begin{array}{c}\text { Job Details: } C_{519} \text { s mutated } \\
E={ }_{0.40} E_{\text {rep }+-0.40} E_{\text {att }+600} E_{\text {elec }+1.00} E_{\text {DAR }}\end{array}$} & \multirow[b]{2}{*}{ Weighted Score } \\
\hline & Members & Representative & \\
\hline \multirow{3}{*}{0} & & Center & -1077.7 \\
\hline & 99 & & \\
\hline & & Lowest Energy & -1203.9 \\
\hline \multirow{3}{*}{1} & & Center & -1008.8 \\
\hline & 67 & & \\
\hline & & Lowest Energy & -1128.6 \\
\hline \multirow{3}{*}{2} & & Center & -890.7 \\
\hline & 66 & & \\
\hline & & Lowest Energy & -1099.2 \\
\hline \multirow{3}{*}{3} & & Center & -975.8 \\
\hline & 57 & & \\
\hline & & Lowest Energy & -1156.1 \\
\hline \multirow{3}{*}{4} & & Center & -1029.4 \\
\hline & 36 & & \\
\hline & & Lowest Energy & -1147.1 \\
\hline
\end{tabular}




\begin{tabular}{|c|c|c|c|}
\hline \multicolumn{4}{|c|}{$\begin{array}{l}\text { Job Details: } C_{519} \text { S mutated } \\
E={ }_{0.40} E_{\text {rep }+-0.40} E_{\text {att }+600} E_{\text {elec }+1.00} E_{\text {DARS }}\end{array}$} \\
\hline Cluster & Members & Representative & Weighted Score \\
\hline \multirow{3}{*}{5} & & Center & -905.0 \\
\hline & 36 & & \\
\hline & & Lowest Energy & -1076.8 \\
\hline \multirow{3}{*}{6} & & Center & -1025.0 \\
\hline & 33 & & \\
\hline & & Lowest Energy & -1105.5 \\
\hline \multirow{3}{*}{7} & & Center & -914.5 \\
\hline & 31 & & \\
\hline & & Lowest Energy & -1029.0 \\
\hline \multirow{3}{*}{8} & & Center & -871.4 \\
\hline & 26 & & \\
\hline & & Lowest Energy & -1027.0 \\
\hline
\end{tabular}

\begin{tabular}{|c|c|c|c|}
\hline \multicolumn{4}{|c|}{$\begin{array}{c}\text { Job Details: IL-2 proteins } \\
E={ }_{0.40} E_{\text {rep }+-0.40} E_{\text {att }+600} E_{\text {elec }+1.00} E_{\text {DARS }}\end{array}$} \\
\hline Cluster & Members & Representative & Weighted Score \\
\hline \multirow{3}{*}{0} & & Center & -859.8 \\
\hline & 186 & & \\
\hline & & Lowest Energy & -1052.5 \\
\hline \multirow{3}{*}{1} & & Center & -1037.4 \\
\hline & 123 & & \\
\hline & & Lowest Energy & -1348.9 \\
\hline \multirow{3}{*}{2} & & Center & -965.5 \\
\hline & 62 & & \\
\hline & & Lowest Energy & -965.5 \\
\hline \multirow[b]{2}{*}{3} & & Center & -850.2 \\
\hline & 61 & Lowest Energy & -850.2 \\
\hline \multirow{3}{*}{4} & & Center & -762.8 \\
\hline & 46 & & \\
\hline & & Lowest Energy & -852.6 \\
\hline \multirow{3}{*}{5} & & Center & -821.2 \\
\hline & 45 & & \\
\hline & & Lowest Energy & -821.2 \\
\hline \multirow{3}{*}{6} & & Center & -790.1 \\
\hline & 43 & & \\
\hline & & Lowest Energy & -847.1 \\
\hline \multirow{3}{*}{7} & & Center & -740.8 \\
\hline & 38 & & \\
\hline & & Lowest Energy & -1235.2 \\
\hline \multirow[b]{2}{*}{8} & & Center & -814.2 \\
\hline & 36 & Lowest Energy & -915.0 \\
\hline
\end{tabular}

ClusPro should only be used for noncommercial purposes.

ABC Group and Structural Bioinformatics Lab

Boston University and Stony Brook University 
assessment by MolProbity and SAVES showed the reliability of the predicted models. On the other hand, molecular docking study by Hex, Pydock, and ZDock software showed that C519S-mutated protein has a higher affinity to IL-2 R compared with DT389IL-2.

However, these two proteins had lower affinity than IL-2 to IL-2 R. According to the pioneer paper entitled 'The Biological Functions of Low-Frequency Phonons' [23] published in 1977, a series of studies and investigations have been stimulating on biomacromolecules from the perspective of the dynamic point. Following this work, many remarkable biological functions and deep dynamic mechanisms in proteins and DNA levels were determined. Besides the understanding of the ligand-binding mechanism and assessment of the protein receptor interaction, we should consider both the static structures concerned and the dynamic information obtained using simulating their internal motions or dynamic procedure. We should direct our efforts in these areas in our next study.

The knowledge of a binding pocket into the protein receptor for its ligand is essential for pharmaceutical protein design, mainly performing mutagenesis investigations [24]. In previous work, the ligand-binding pocket into the protein receptor is usually defined by those residues that have at least one heavy atom other than hydrogen within $5 \AA$ distance from a heavy atom of the ligand. Initially, such a practical criterion was used to define the ATP binding pocket in the Cdk5-Nck5a* complex [25]. This criterion was later proved quite useful in the functional domains identification and the stimulation of relevant truncation experiments [26]. Also, a similar method was used to define the binding pockets of many other receptor-ligand interactions that are important for the design of drugs [27].

Openly accessible and user-friendly web servers present the next direction for reporting various influential computational studies and analyses [28]. With this approach, the impacts of computational biology on medical science hold significant promises for an unprecedented revolution [29].

In conclusion, the substitution of Cysteine 519 with a serine residue with the aim of proper folding has neither adverse effect on the structure nor the binding affinity of the protein to IL-2 R. Therefore; the mutated protein can substitute DT389IL-2 production and improve the refolding process of this fusion protein.

\section{Ethical Considerations}

\section{Compliance with ethical guidelines}

All ethical principles were considered in this article.

\section{Funding}

This research did not receive any specific grant from funding agencies in the public, commercial, or not-forprofit sectors.

\section{Authors contribution's}

All authors contributed in preparing this article.

\section{Conflict of interest}

The authors declared no conflict of interests.

\section{Acknowledgements}

The authors would like to thank the research council of the Faculty of Chemistry and Chemical Engineering of Malek Ashtar University of Technology for the financial support of this project.

\section{References}

[1] Cappello J, Crissman J, Dorman M, Mikolajczak M, Textor G, Marquet M, Ferrari F. Genetic engineering of structural protein polymers. Biotechnol Prog. 1990; 6(3):198-202. [DOI:10.1021/bp00003a006] [PMID]

[2] Aisenbrey C, Salnikov ES, Raya J, Michalek M, Bechinger B. Solid-State NMR Approaches to Study Protein Structure and Protein-Lipid Interactions. InLipid-Protein Interactions. New York: Humana, 2019. [DOI:10.1007/978-1-4939-9512-7_23] [PMID]

[3] Abriata LA, Tamò GE, Dal Peraro M. A further leap of improvement in tertiary structure prediction in CASP13 prompts new routes for future assessments. Proteins. 2019; 87(12):1100-12. [DOI:10.1002/prot.25787] [PMID]

[4] Weissleder R, Pittet MJ. Imaging in the era of molecular oncology. Nature. 2008; 452(7187):580. [DOI:10.1038/nature06917] [PMID] [PMCID]

[5] Schrama D, Reisfeld RA, Becker JC. Antibody targeted drugs as cancer therapeutics. Nat Rev Drug Discov. 2006; 5(2):147. [DOI:10.1038/nrd1957] [PMID]

[6] Sun X, Ponte JF, Yoder NC, Laleau R, Coccia J, \& Lanieri L. Effects of drug-antibody ratio on pharmacokinetics, biodistribution, efficacy, and tolerability of antibody-maytansinoid conjugates. Bioconjug Chem. 2017; 28(5):1371-81. [DOI:10.1021/acs.bioconjchem.7b00062] [PMID] 
[7] Foss FM. DAB389IL-2 (denileukin diftitox, ONTAK): a new fusion protein technology. Clin Lymphoma. 2000; 1:S27-31. [DOI:10.3816/CLM.2000.s.005]

[8] Foss FM, Bacha P, Osann KE, Demierre MF, Bell T, Kuzel T. Biological correlates of acute hypersensitivity events with DAB389IL-2 (denileukin diftitox, ONTAK®) in cutaneous T-cell lymphoma: Decreased frequency and severity with steroid premedication. Clin Lymphoma. 2001; 1(4):298-302. [DOI:10.3816/CLM.2001.n.005] [PMID]

[9] Turturro F. Denileukin diftitox: a biotherapeutic paradigm shift in the treatment of lymphoid-derived disorders. Expert Rev Anticancer Ther. 2007; 7(1):11-7. [DOI:10.1586/14737140.7.1.11] [PMID]

[10] Martin PL, Breslin W, Rocca M, Wright D, Cavagnaro J. Considerations in assessing the developmental and reproductive toxicity potential of biopharmaceuticals. Birth Defects Res B Dev Reprod Toxicol. 2009; 86(3):176-203. [DOI:10.1002/bdrb.20197] [PMID]

[11] Luke JJ, Zha Y, Matijevich K, Gajewski TF. Single dose denileukin diftitox does not enhance vaccine-induced $\mathrm{T}$ cell responses or effectively deplete Tregs in advanced melanoma: immune monitoring and clinical results of a randomized phase II trial. J Immunother Cancer. 2016; 4(1):35. [DOI:10.1186/s40425-016-0140-2] [PMID] [PMCID]

[12] Negrier S, Escudier B, Lasset C, Douillard JY, Savary J, Chevreau C, Ravaud A, Mercatello A, Peny J, Mousseau M, Philip T. Recombinant human interleukin-2, recombinant human interferon alfa-2a, or both in metastatic renal-cell carcinoma. N Engl J Med. 1998; 338(18):1272-8. [DOI:10.1056/ NEJM199804303381805] [PMID]

[13] Liang SM, Thatcher DR, Liang CM, Allet B. Studies of structure-activity relationships of human interleukin-2. J Biol Chem. 1986; 261(1):334-7.

[14] Hambling SG, McAlpine AS, Sawyer L, Fox PF. Advanced Dairy Chemistry 1. London: Elsevier Applied Science; 1992.

[15] Nielsen LR, Lund MN, Davies MJ, Nielsen JH, Nielsen SB. Effect of free cysteine on the denaturation and aggregation of holo a-lactalbumin. Int Dairy J. 2018; 79:52-61. [DOI:10.1016/j.idairyj.2017.11.014]

[16] Wang A, Lu SD, Mark DF. Site-specific mutagenesis of the human interleukin-2 gene: structure-function analysis of the cysteine residues. Science. 1984; 224(4656):1431-3. [DOI:10.1126/science.6427925] [PMID]

[17] Huang DW, Sherman BT, Lempicki RA. Bioinformatics enrichment tools: paths toward the comprehensive functional analysis of large gene lists. Nucleic Acids Res. 2008; 37(1):1-3. [DOI:10.1093/nar/gkn923] [PMID] [PMCID]

[18] Audagnotto M, Dal Peraro M. Protein post-translational modifications: In silico prediction tools and molecular modeling. Comput Struct Biotechnol J. 2017; 15:307-19. [DOI:10.1016/j.csbj.2017.03.004] [PMID] [PMCID]

[19] Chou KC. Insights from modeling the 3D structure of DNA- CBF3b complex. J Proteome Res. 2005; 4(5):1657-60. [DOI:10.1021/pr050135+] [PMID]

[20] Saxon M. Denileukin diftitox. Clin J Oncol Nurs. 2000; 4(6):289-93.
[21] Bayat, Sh., Zeinoddini, M., Azizi, A., \& Khalili, M. N. (2019). Co-Solvents Effects on the Stability of Recombinant Immunotoxin Denileukin Diftitox: Structure and Function Assessment. Iran J Sci Tech, Trans. 43: 2091-97. [DOI:10.1007/ s40995-019-00676-7]

[22] Devrim B, Bozkır A, Canefe K. Preparation and evaluation of poly (lactic-co-glycolic acid) microparticles as a carrier for pulmonary delivery of recombinant human interleukin-2: II. In vitro studies on aerodynamic properties of dry powder inhaler formulations. Drug Dev Ind Pharm. 2011; 37(11):1376-86. [DOI:10.3109/03639045.2011.576680] [PMID]

[23] CHOU KC, Chen NY. The biological functions of low-frequency phonons. Sci Sin. 1977; 20(4):447-57.

[24] Patel B, Singh V, Patel D. Structural Bioinformatics. InEssentials of Bioinformatics. New York: Springer; 2019. [DOI:10.1007/978-3-030-02634-9_9] [PMCID]

[25] Chou KC, Watenpaugh KD, Heinrikson RL. A model of the complex between cyclin-dependent kinase 5 and the activation domain of neuronal Cdk5 activator. Biochem Biophys Res Commun. 1999; 259(2):420-8. [DOI:10.1006/ bbrc.1999.0792] [PMID]

[26] Zhang J, Luan CH, Chou KC, Johnson GV. Identification of the N-terminal functional domains of Cdk5 by molecular truncation and computer modeling. Proteins. 2002; 48(3):447-53. [DOI:10.1002/prot.10173] [PMID]

[27] Huang RB, Du QS, Wang CH, Chou KC. An in-depth analysis of the biological functional studies based on the NMR M2 channel structure of influenza A virus. Biochem Biophys Res Commun. 2008; 377(4):1243-7. [DOI:10.1016/j. bbrc.2008.10.148] [PMID]

[28] Cheng X, Xiao X, Chou KC. pLoc-mPlant: predict subcellular localization of multi-location plant proteins by incorporating the optimal GO information into general PseAAC. Mol Biosyst. 2017; 13(9):1722-7. [DOI:10.1039/C7MB00267]] [PMID]

[29] Chou KC. An unprecedented revolution in medicinal chemistry driven by the progress of biological science. Curr Top Med Chem. 2017; 17(21):2337-58. [DOI:10.2174/1568026 617666170414145508] [PMID] 